\title{
Biography of Dr. Charles U. Pittman, Jr.
}

\author{
Charles E. Carraher Jr.
}

Published online: 25 May 2010

(C) Springer Science+Business Media, LLC 2010

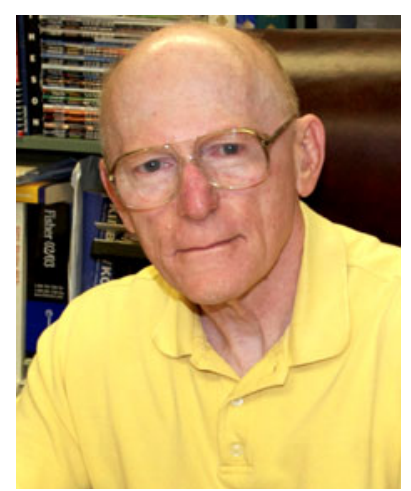

I have known Charles U. Pittman, Jr. for 40 years, most of our research lives. I know him as a fellow researcher but more so as a friend. This special issue of JIOPM is dedicated to him in recognition of his many contributions to metal-containing polymers and as one of the fathers of this rapidly expanding and important area.

His legacy finds many horizons- - his family, his friends, his students and his research contributions. He has directed over $40 \mathrm{PhD}$ students, $20 \mathrm{MS}$ students, 20 postdoctoral fellows and counting. He is a co-father of the research area we call metal-containing polymers, co-founder of the JIOPM, and co-founder of the Wiley series Macromolecules Containing Metal and Metal-Like Elements. He has published over 700 refereed papers, books and patents. He has presented over 400 invited lectures and has been supported by NSF, ARO, ONR, PRF, EPA, DOE, Research Corp., $\mathrm{NIH}$ and numerous private sources. For 10 years, he was editor of the Journal of Molecular Catalysis. He was a contributing editor to Polymer News and has been on the

C. E. Carraher Jr. ( $₫)$

Florida Atlantic University, Boca Raton, FL, USA

e-mail: carraher@fau.edu editorial boards of Journal of Macromolecular Science, Inorganic Chimica Acta, Reactive Polymers and the Journal of Inorganic and Organometallic Polymers. He is coeditor of 18 books.

Charles was born in Rahway, NJ on Oct 26, 1939. He played football and ran track at Penn Hills High School and graduated in 1957 with high honors. This was the official start of his track efforts that continues today. A sprinter throughout high school and 4 years of college, he also ran AAU for several years. He attended Lafayette College earning a BS in Chemical Engineering in 1961 (Magna Cum Laude, Phi Beta Kappa). From there he moved to Pennsylvania State University from Sep 1961 to Sep 1964 when he completed a $\mathrm{PhD}$ in Chemistry (organic major) at age 24. In Sep 1964 to Dec 1965 he completed a postdoctoral fellowship with George Olah, first at Dow Chemical's Eastern Regional Research Laboratory in Waylan Mass, and then moved with him to Case Western Reserve University. In Dec 1965, he went on active duty in the US Army (Ordinance Corps). His permanent duty station was Redstone Arsenal where he became a rocket scientist working in the US Army Solid Rocket Propulsion Lab (as a Captain). He published in both the classified and in the open literature while in the Army.

In 1967, Dr. Pittman joined the faculty at the University of Alabama, Tuscaloosa. He was appointed Full Professor in 1975 and University Research Professor in 1977. Dr. Pittman came to Mississippi State in 1983 as Professor of Industrial Chemistry and Catalysis. $\mathrm{He}$ is founder and Research Director of the University/Industry Chemical Research Center.

Over the past 20 years, Dr. Pittman transferred basic research into the private sector for commercial development to aid economic growth in the state of Mississippi. For example, three patents on hydroxylamine-based plasma 
etch debris cleaners led to an over $\$ 100$ million/year business in the semiconductor industry. As research director of the University/Industry Chemical Research Center he has worked to bring in industrial contract research to support the state and graduate students. He also holds a number of basic patents in diverse areas including polyurethane impregnated wood with surface coatings, liquid thioxanthone photoinitiators and photopolymerization compositions containing them, cleaning compositions including nucleophilic amine compounds having reduction and oxidation potentials, ammelin-melamine-formaldehyde resins and their preparation, selective $\mathrm{N}$-alkylation of anilines using shape selectivity inside zeolites, delineating a desired integrated circuit pattern using a circuit substrate, 1,7-octadiene from butadiene and others on solid-propellant rocket liners and ablation resistant rocket nozzles.

His research spans the fields of organic, organometallic, polymer, inorganic, environmental chemistry, and toxicology, computational chemistry and composite and nanocomposite materials. He pioneered the synthesis of organotransition metal monomers and the kinetics of their homo- and copolymerization in the physical/organic and mechanistic aspects through early characterization. Also, early studies of mixed valance semiconducting ferrocene polymers came from his group. Here organic, polymer, and inorganic chemistry merge.

In addition, he pioneered the area of anchoring homogeneous transitional metal catalysts to polymer supports to carry out single and multistep reactions in batch and flow systems, where the advantages of heterogeneous catalysis were merged with the selectivity and tunability of homogeneous catalysts. Investigations were carried out on the effect of ligands on rates and selectivity of these reactions, the use of asymmetric ligands to achieve asymmetric catalysis, and the photogeneration of catalytically active intermediates. In these studies organic reactions of commercial importance such as alkoxycarbonylations, hydroformylations, hydrogenations, methanol homologation, and diene oligomerizations have been studied using catalysts from the world of inorganic chemistry.

Charles was also one of the early investigators of the use of dinuclear metal compounds and metal clusters as homogeneous catalysts in the search for new types of catalytic activity, answering if clusters fragment and proving that a chiral cluster induced asymmetric conversions.

He employed ab initio quantum mechanical calculations (HF and DFT) to a variety of organic and inorganic systems. $\mathrm{Ab}$ Initio quantum mechanical calculations have been employed to characterize the response surfaces of $\mathrm{B}$, $\mathrm{N}, \mathrm{C}$ ring and linear systems including $\mathrm{C}_{2} \mathrm{H}_{2} \mathrm{BN}, \mathrm{H}_{2} \mathrm{BN}$, $\mathrm{C}_{2} \mathrm{H}_{2} \mathrm{~N}_{2}, \mathrm{~B}_{2} \mathrm{~N}_{2}$, etc. POSS systems including optimized structures of the $\mathrm{T}_{8^{-}}, \mathrm{T}_{10^{-}}$and $\mathrm{T}_{12^{-}}$cages have and are being investigated along with their endohedral complexes with metal ions (alkali, alkaline, transition metals), halides and noble gases by Dr. Pittman's group. Alkali metal and halide exohedral complexes are also being studied. Silicon clusters $\mathrm{Si}_{n} \mathrm{M}$, where $n=10-20$, containing a transition metal $\mathrm{M}$ and a variety of other metal clusters such as $\mathrm{Au}_{32}$, containing an endohedral $\mathrm{Au}_{12} \mathrm{~W}$, are being investigated.

His group helped develop new generations of electronbeam, X-ray and chemically amplified resist polymers for use in sub-micron lithography. Novel polymers, copolymers and terpolymers have been constructed; their radiation degradation behavior and sensitivity as resists studies and their thermal stabilities were characterized. Cationic polymerizations of cyclic ketene acetals and their $\mathrm{N}$ and $\mathrm{S}$ analogs are currently being examined.

Novel organic compounds such as tetrathiafulvalene (TTF) form conducting salts when reacted with such electron acceptors as tetracyanoquinodimethane (TCNQ). Organic synthetic approaches to a variety of TTF/TCNQ analogs and to their incorporation into polymers have been carried out by his group.

Charles has led the use of dehalogenation reactions using $\mathrm{Ni}^{2+}$-promoted alkoxyborohydrides, solvated electrons $\left(\mathrm{Na} / \mathrm{NH}_{3}\right.$ or $\left.\mathrm{Ca} / \mathrm{NH}_{3}\right)$ and other strongly basic media. These have been developed for detoxification of PCBs, CAHs and pesticides in the environment. Remediation of soils and sludges from superfund sites using $\mathrm{Na} / \mathrm{NH}_{3}$ and $\mathrm{Na}$ consumption per dehalogenation event as a function of contaminant concentration and water were studied.

His polymer interests have extended into polymer blends, semi-interpenetrating and interpenetrating polymer networks, polymerization of $\alpha$-methylene lactones and lactams and the cationic (both 1,2-addition and ringopening) polymerizations of cyclic ketene-O,O-acetals (and their O,N and O,S and S,N analogs).

More recently, he has emphasized aspects of computational chemistry on polycalicenes, Si tubes and clusters, gold clusters and the subject of his contribution to this issue, host/ guest chemistry of POSS complexes. His research on fiberous composite materials development is focused on fiber surface functionalization followed by the designed synthesis of a polymeric elastomer interphase layer chemically bonded to the fiber. This is then chemically bound into the matrix so that a totally bonded three phase composite system is constructed. The surface analysis of treated carbon nanofibers and the designed organic chemistry on these surfaces have been studied by his group with vapor grown carbon fibers in composites currently being studied.

Conversion of biomass to bio-oil by fast pyrolysis is also a recent, research theme. Joint with the Mississippi Forest Products Laboratory, Professor Pittman has converted wood, sawdust and bark to bio-oil in an auger-fed reactor. Solvent fractionation of bio-oil to isolate the pyrolytic lignin-rich fraction is being studied as a wood preservative 
and its polymerization is being explored. With the need to reduce greenhouse gas emissions, the production of fuels from biomass is becoming an increasingly important topic. $\mathrm{He}$ is developing an upgrading process based on bio-oil additions across olefin streams. If biomass-to-fuel production occurs on a large scale in the future, one can predict that biorefineries will emerge from which chemical product streams will result. Thus, catalytic chemical transformations from biomass to chemicals are now a significant current area of research of Chuck's group.

Cyclic ketene-O,O (and N,O and N,S)-acetals are highly nucleophic functions combining two vinyl ether groups or a vinyl ether and an enamine moiety in the same functional group, simultaneously. Pittman has developed a series of novel cyclizations with dielectrophiles leading to a variety of fused heterocyclic ring systems and steroselective ringopening reactions as part of his current "pure" organic research.

Among the journals that Charles has published in 2009 are Structural Chemistry, Bioresources Technology, European Journal of Organic Chemistry, Composites, Chemistry of Materials, Talanta, Tetrahedron Letters, Separation and Purification Technology, Fuel, Journal of Materials Science, Synthesis and Tetrahedron. This year (2010) he has papers in Tetrahedron, Synthesis, Bioresources Technology, Industrial \& Engineering Chemistry Research, Chemical Journal of Chinese Universities, Journal of Composites and the Forest Products Journal. It illustrates the diversity and activity that he has had for over 40 years. This activity continues though he is somewhat retired. In his retirement he is doing more than most do during their most active periods.

$\mathrm{He}$ has contributed a number of valuable reviews starting with a Chemical Reviews article on dioxolinium and dioxenium ions in 1975. Recent examples include his critical review of the removal of arsenic from water using adsorbents (i.e., "Arsenic removal from water/wastewater using adsorbents," Journal of Hazardous Materials (2007), 142(1-2), 1-53). Another review discusses the removal of chromium from water using activated carbons and low cost adsorbents (i.e., "Activated carbons and low cost adsorbents for remediation of tri- and hexavalent chromium from water," Journal of Hazardous Materials (2006), 137(2), 762-811). Another describes the production of photoluminescent materials based on fullerenes that illustrates interest in photochemistry and photophysics (i.e., "Photoluminescent materials based on laser-modified fullerenes-doped polymer thin films," in "Thin Films and Coatings," 1-26, Nova Science Publishers, Inc., Hauppauge, N.Y. 2005). Chuck's review of the pyrolysis of wood/ biomass for bio-oil (i.e., "Pyrolysis of Wood/Biomass for Bio-oil: A Critical Review" in Energy \& Fuels (2006), 20(3), 848-889) was the most assessed publication in Energy and Fuel in 2006-2008 and is still the fourth most assessed so far in 2010. Another basic science review describes the synthesis and properties of homopolymers and copolymers of monomers containing inorganic-organic hybrid polyhedral oligomeric silsesquioxane (POSS) structures; (i.e., "Polyhedral oligomeric silsesquioxane (POSS) polymers and copolymers," in Journal of Inorganic and Organometallic Polymers (2002), 2001, 11(3), 123-154).

His research efforts with metal-containing polymers has been recently reviewed in a number of publications including Organometallic polymers: the early days, in "Frontiers in Transition Metal-Containing Polymers," 1-44, John Wiley \& Sons, Inc., Hoboken, N. J. 2007, pp. 1-44) and in Macromolecules Containing Metal and Metal-Like Elements. Vol. 1, A Half Century of Metal- and MetalloidContaining Polymers, Wiley, Hoboken, N.J., 2003. A bibliography of Charles' publications is found at the Mississippi State University web site for the Department of Chemistry (http://www.mstate.edu/dept/chemistry/rschcp.htm).

I asked Charles how he got interested in science; his response was "As a child I loved collecting snakes, bird nests, coins, stamps, insects, spiders and reading National Geographic." In high school he noted that girls never needed help in English or music. However, they always seemed to want to ask for his help in chemistry and physics. So how could one not be attracted to these subjects? A science major was born.

How did Charles' track prowess dovetail with him being a professor? From the time he started teaching in 1967 at the University of Alabama, he would cajole his class into getting some extra points on a test if they would come to the track with others in the class and beat him in a $200-\mathrm{m}$ race. He continued this offer until he was 62-and never had to give away points. He heaped much fun, or perhaps you could call it abuse, in class on the following day on those who couldn't beat the 'old guy'. In more recent years he has been careful to whom he made this offer; but, the stories continue to abound around campus. 